and the structure of its physician quality improvement (QI) programs was recognized for inclusion in the pilot MOC Portfolio Approval Program.

As an MOC Portfolio Sponsor, Mayo Clinic has primary ownership of the design and execution of a large number of QI activities that are managed centrally through an established infrastructure and overseen by a formal governance body. Mayo Clinic will also accept accountability for ensuring the activities meet the standards outlined by the 3 boards and for management of the QI activities.

While the ABFM, the ABIM, and the ABP have individually recognized other organizations' QI products and programs for MOC credit in the past, Mayo Clinic is the first organization to be recognized, jointly, by all 3 boards. The 3 primary care boards expect to approve 2 to 4 additional portfolio sponsor organizations in the next 3 years as part of this effort

"We are proud that Mayo Clinic is the first organization recognized by the 3 largest certifying boards and believe that this is a testament to Mayo's leadership in quality improvement," said Richard Berger, MD, Dean of the Mayo School of Continuous Professional Development. "We believe rigorous quality improvement efforts make better physicians, improve the systems of care that physicians work in, and, most importantly, enhance patient care, furthering Mayo Clinic's leadership in the practice of medicine. We are delighted that family physicians, internists, and pediatricians who are engaged in QI activities every day will receive MOC credit for their hard work."

Research has shown that fewer than $30 \%$ of physicians examine their own performance data, and physicians' ability to independently self-assess and selfevaluate is poor. Each certifying board requires physicians to look at their practice and make improvements. Mayo Clinic has established QI activities in its clinical setting that meet the three primary care boards' requirements for improving performance in practice.

"We look forward to recognizing other programs that engage physicians in rigorous quality improvement activities" said James A. Stockman, MD, President and CEO of the American Board of Pediatrics. "Physicians want to deliver the best care possible to their patients, and these programs help them understand where improvement is needed and give them a structured environment to make positive changes."

Mayo Clinic's Quality Review Board will evaluate Mayo physicians' participation in structured QI activities to determine if they meet the boards' requirements for MOC. Among the requirements for MOC approval:

- Projects must focus on 1 of the Institute of Medicine's (IOM) 6 dimensions of quality (ie, making health care more safe, effective, patient-centered, timely, efficient, and equitable)

- Physicians must provide direct or consultative care to patients as part of the QI project or actively participate in the process of care being addressed by the project. This includes physicians who actively supervise a trainee (resident or fellow) during a QI project

- Physicians must demonstrate active collaboration in QI project design and/or implementation, such as team meetings, data analysis, implementation training, etc

"MOC is a multi-faceted program that includes knowledge and continuous improvement," said Christine Cassel, MD, President and CEO of the American Board of Internal Medicine. "We look for opportunities to reduce the administrative burden for physicians, but still ensure that they are meeting our high standards of self evaluation and quality improvement."

"The 3 primary care boards are working together to develop novel programs that can be used to maintain certification, and this collaborative pilot with Mayo Clinic represents just 1 of our innovative projects," said James C. Puffer, MD, President and CEO of the American Board of Family Medicine. "We continue to explore next generation approaches to quality improvement, including those that interface with integrated health care systems, community-based medical groups, and the individual physician's practice."

Kevin Graves

American Board of Family Medicine American Board of Internal Medicine American Board of Pediatrics

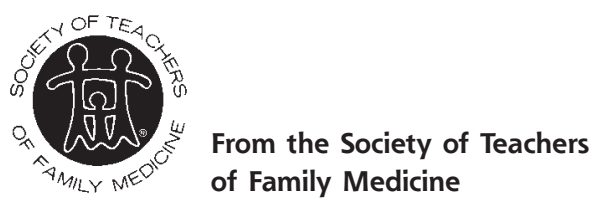

Ann Fam Med 2010;8:182-184. doi:10.1370/afm.1102.

\section{At STFM, Advocacy is a Verb}

The prospect of dramatic health care reform has spurred increased interest in governmental advocacy by STFM members. For some, the potential strain of primary health care needed by millions of newly insured Americans has struck a chord of anxiety and sparked an interest in advocacy. Most STFM members, however, welcome the opportunity to be participants in health system change that promotes primary care and its corollary benefits to society. 
Since the first draft of this article, the loss of a 60 -vote Democratic majority in the Senate has made immediate passage of reform legislation less likely. Regardless, our work is cut out for us. New legislation would bring a myriad of opportunities and challenges, and STFM and its members must stand ready to think creatively, respond rapidly, and influence effectively. Should health care reform fail, our work is to assure that another generation doesn't pass before Congress addresses reform again.

It is our hope that the enthusiasm engendered this year will be harnessed and used for even more effective advocacy efforts. Each family medicine educator and primary healthcare professional should carefully assess his or her role in advocacy in the new healthcare construct. These questions are essential:

1. What items for health care reform are most important for an effective, efficient, equitable system?

2. What items are most important to impact the medical education system to train the workforce needed for such a system?

3. What should I do if I haven't participated in advocacy efforts yet?

4. Do those currently active in advocacy efforts really need my help?

A loud, unified voice from family medicine is needed, and STFM provides the organizational structure for you to be an effective advocate.

\section{Organization of Governmental Advocacy at STFM}

Family medicine organizations operate cooperatively in the advocacy arena. STFM conducts federal legislative and regulatory advocacy through its office in Washington, DC. The 4 academic family medicine organizations (STFM, ADFM, AFMRD, and NAPCRG) jointly support an office and staff in Washington under the banner of the Council of Academic Family Medicine (CAFM). Hope Wittenberg (Director, Government Relations) and Joe Cody (Government Relations Assistant) monitor, analyze, and advocate for legislation important to academic family medicine.

This office also supports 2 governmental advocacy committees. One is the STFM legislative affairs committee, chaired by Dr Jerry Kruse, and the other is the Academic Family Medicine Advocacy Committee (AFMAC), which has representatives from STFM, ADFM, AFMRD, NAPCRG, and the AAFP. These committees develop policy for key issues such as Title VII funding and operation, Medicare Graduate Medical Education (GME) structure and funding, primary care research, and primary care workforce development.

\section{STFM Advocacy Agenda}

The DC office advocates on behalf of academic family medicine to Congress and to agencies of the Executive Branch. The DC office assists members with analysis of legislation, provision of legislative updates and briefings, and transmission of alerts to members about issues important to academic family medicine.

The DC office regularly meets with legislators and their staffs, and with executive agencies, to discuss funding for Title VII. During the appropriations process, STFM advocates for increased Title VII funding to better support family medicine infrastructure and programs. This advocacy, coupled with a renewed commitment from the Obama administration and Congress, led to a substantial increase in appropriated funding for Title VII this year. The DC office has also been integrally involved with the reauthorization of Title VII, and reauthorization language in now included in both the House and Senate healthcare reform bills.

GME reform is a key area for family medicine, and the DC office promotes policies to develop a more robust primary care workforce. In 2008, the STFM Legislative Affairs Committee and AFMAC responded quickly to the Medicare Payment Advisory Commission's call for more accountability in GME with a dramatic proposal to improve the Medicare GME process. Since then, the DC office has launched an advocacy campaign for this plan, which proposes to make direct GME payments to primary care residency programs and community-based entities, and to ensure adequate incentives for training in ambulatory and communitybased settings.

The DC office analyzes legislation and its effect on healthcare and on the discipline of family medicine. Policy papers and one pagers, and brief overviews are provided on the STFM Web site, along with legislative updates in the CAFM Briefing Room http://www.stfm. org/advocacy/.

The AAFP and CAFM jointly sponsor the annual Family Medicine Congressional Conference (FMCC). The DC office is intimately involved in the development of the agenda for FMCC. This conference educates participants on legislative priority issues, trains attendees on how to lobby on Capitol Hill, and enables participants to put these skills to use with federal legislators and their staff (http://www.aafp.org/fmcc). The FMCC has become a major tool for faculty development in advocacy skills, both in Washington, and within your academic institution and community.

\section{Role of STFM Members}

The DC office is a resource that helps clarify the intricacies of the legislative process and is instructive in 
advocacy efforts, but is dependent on the active participation and leadership of STFM members. Congress listens to those who provide care and teach. Here is what our colleagues say about advocacy

Dan Lasser, MD, Chair, University of Massachusetts: "When you start doing this, you learn that the members of Congress and other people who are involved with policy actually do want to hear from constituents and people that have concerns about health policy and we have a lot to offer to the whole legislative and health policy process."

Jeffrey Borkan, MD, PhD, Chair, Brown University: "If we are not out there [advocating], we are going to continue to have a medical system that looks the way it is, if we are not out there, people are not going to get care."

Jeffrey Cain, MD, Denver, CO: "The same lessons we learn for teaching medical students work for teaching legislators."

What these colleagues realize is that advocacy starts from the heart, with a message for better healthcare-and the process flows easily from there. Dr Cain continued his earlier comments, "I didn't start out being an advocate I just wanted to help protect kids from tobacco. We started doing Tar Wars and found out those lessons we learned about advocacy with kids health transferred into legislative advocacy too".

Likewise, Dr Kruse, the current chair of the STFM Legislative Affairs Committee, didn't start as an advocate. With the encouragement of colleagues, he became involved in ADFM and STFM advocacy, and can speak to the rewards of advocacy through the development of relationships with people in the offices of senators and representatives. Because family physicians are armed with the strongest and most elegant data, it generally takes only a few visits to become a trusted healthcare advisor to the legislators and their staff.

STFM has much to offer to help you develop skills in advocacy. The DC office is there to help. Please call our staff in Washington about any question you may have about the legislative process, or about specific legislation, policies, or advocacy tips. We salute those who are committed to advocacy, and ask for continued involvement. We ask a new generation of advocates to step forward to amplify the message. If you do, health and health care in the United States will improve.

Hope Wittenberg, MA

STFM Director, Government Relations Jerry Kruse, MD, MSPH

Chair, STFM Legislative Affairs Committee

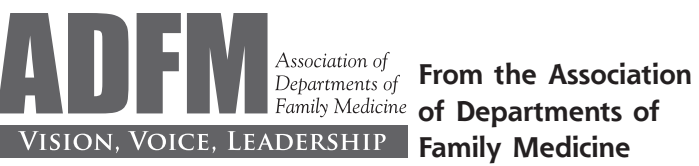

Ann Fam Med 2010;8:184-185. doi.10.1370/afm.1100.

\section{How to Manage the Pace of Practice Innovation Information Flow and Change? Introducing the ADFM Patient Centered Medical Home Taskforce}

These are exciting times for family medicine/primary care, and departments of family medicine are increasingly engaged in clinical innovation in order to meet the needs of our patients and our discipline. ${ }^{1}$ Keeping up with the rapid flow of information and change presents a major challenge: How to coordinate the active and ever-moving dialogues regarding PCMH with local, regional and national leaders, and garner insights from the cacophony of demonstration projects and initiatives into useable information for our members and their departments? How do we incorporate all of the missions of academic departments (clinical, educational and scholarship) into curricular redesign and clinical effectiveness research, in addition to the clinical practice transformation required?

As described in the Nov/Dec 2009 issue of the Annals of Family Medicine, ADFM is working with the Patient Centered Primary Care Collaborative (PCPCC) to further our own departments' strengths and evolution in clinical areas related to the Patient Centered Medical Home (PCMH). However, even within this one organization there is an ever increasing number of initiatives, centers, communication mechanisms, and publications, from which are a host of emerging allied enterprises, Web sites, and resources. ADFM leadership is desirous of creating an ongoing method for distilling down the breadth of this rapidly moving target, as well as to utilize the talents of our members to create a proactive dialogue of ideas and information back to PCPCC and other PCMH entities. To accomplish this, a new PCMH task force in ADFM has been formed to support, stimulate and monitor this synergistic exchange between Departments of Family Medicine and the Patient Centered Primary Care Collaborative, NCQA, CAFM, and other groups with similar activities. The overarching goal of the task force is to facilitate ADFM and family medicine playing an active role in the evolving PCMH domain, with 3 specific objective as illustrated below:

1. Information Clearinghouse - to serve as a source 